\title{
Tratados internacionais em âmbito interno: uma discussão sobre 0 ato da denúncia unilateral pelo presidente da república sem a participação do poder legislativo
}

\author{
Marcelo Veríssimo Ferreira \\ Graduando em Direito pelo Centro Universitário de Barra Mansa - UBM. \\ Estagiário do Núcleo de Prática Jurídica do NPJ. \\ marcelovf-2012@hotmail.com
}

Sérgio Luís Pacheco Machado Júnior

Mestre e Advogado com atuação nas áreas de Direito civil e empresarial, sócio do escritório Poubel \& Machado Advogados Associados. Mestre em Direito, Especialista em Direito Empresarial (2009); e graduado em Direito (2008) todos pelo Centro Universitário Salesiano de São Paulo - UNISAL (Lorena/SP). Professor do Curso de Graduação em Direito do Centro Universitário de Barra Mansa - UBM (Barra Mansa/RJ). Professor do Curso de Pós-Graduação (lato sensu) do Centro Universitário Salesiano de São Paulo - UNISAL (Lorena/SP). Professor do Curso Preparatório Mestra Educacional. sergiomachadojunior@gmail.com 


\section{Resumo}

Este trabalho teve, como ponto de partida, a demonstração do conceito básico de um tratado, bem como os requisitos e etapas de elaboração de compromissos internacionais. Ademais, com a intenção de discutir acerca de seus meios de extinção, notadamente a denúncia em âmbito interno. O presente artigo, fruto de uma monografia, buscou estabelecer comparativos entre posicionamentos jurídicos divergentes quanto ao procedimento do instituto, no que tange à necessidade ou não de autorização parlamentar para viabilizá-lo, além de enfatizar certas distinções inerentes aos tratados internacionais de direitos humanos e, finalmente, analisar uma ação direta de inconstitucionalidade, relativa ao tema, ora em trâmite junto ao Supremo Tribunal Federal.

Palavras-chave: Tratados Internacionais. Denúncia Unilateral. Direitos Humanos. Congresso Nacional. Presidente da República.

\section{Abstract}

This work had, as a starting point, the demonstration of the basic concept of a treaty, as well as the requirements and stages of elaboration of international commitments. In addition, with the intention of discussing about its means of extinction, notably the internal withdrawal, this monograph sought to establish comparisons between different legal positions regarding the procedure of the institute, regarding the necessity or not of parliamentary authorization to make it viable, as well as to emphasize certain distinctions inherent in international human rights treaties, and finally, to analyze a direct action of unconstitutionality, related to the subject, now being processed by the Federal Supreme Court.

Keywords: International Treaties. Unilateral Withdrawal. Human Rights. National Congress. President of the Republic. 


\section{Introdução}

A sociedade internacional, desde a eclosão das primeiras relações interestatais, é pautada por constantes evoluções nos mais diversos segmentos; e, nesse sentido, o Direito, mais especificamente os tratados, atua, principalmente, como via de normatização desses laços. Sendo, essencialmente, um ajuste de vontades, é perfeitamente possível que, após sua regular conclusão e exaurimento de seu conteúdo, um tratado se extinga, haja vista que os avanços da realidade internacional podem ocasionar a perda de interesse acerca de seu objeto e, nesse sentido, a "denúncia" constitui uma das principais formas de seu rompimento.

Entretanto, dada a ausência de normas procedimentais que estabeleçam diretrizes atinentes a tal instituto, coexistem, no ordenamento jurídico pátrio, posições díspares no que tange ao seu modo de procedibilidade.

Destarte, o objeto de discussão do presente artigo científico consiste na análise doutrinária de tais divergências, no que se refere à necessidade (ou não) de aprovação do Poder Legislativo, para que o Presidente da República denuncie um tratado.

Nesse sentido, preliminarmente, abordar-se-ão o conceito preliminar de um tratado, bem como os requisitos essenciais à sua validade, além de suas etapas de elaboração.

Em seguida, tratar-se-á da "denúncia” como forma de extinção de um tratado, especialmente no que tange à necessidade ou não de autorização legislativa para executá-la, tanto em relação aos atos comuns, como aos que versam sobre direitos humanos.

Por fim, analisar-se-á os desdobramentos e atual fase de tramitação da ação direta de inconstitucionalidade $\mathrm{n}^{\circ}$ 1625/DF, cujo julgamento, pelo Supremo Tribunal Federal, estará apto a, derradeiramente, pôr termo à referida discussão.

No presente trabalho, será utilizado, como abordagem metodológica o levantamento bibliográfico e jurisprudencial, típico nas pesquisas de Direito e utilizarse-á a análise dedutiva para formulação das considerações finais. Foram analisados os livros e periódicos com artigos científicos sobre o tema em epígrafe, na qualidade de fontes secundárias. Também foi estudada a ação direta de inconstitucionalidade, ora em trâmite junto à Suprema Corte. 


\section{Conceito e requisitos de validade de um tratado}

O tratado internacional, em sua acepção mais moderna, refere-se a um acordo, firmado por escrito e celebrado por Estados ou organizações internacionais, visando a gerar efeitos jurídicos em relação a objetos de interesse comum, podendo ser bilateral ou multilateral. (PORTELA, 2011).

Destarte, esse conceito permite constatar que tal instrumento normativo é criado mediante a convergência de vontades de alguns atores da sociedade internacional, de forma que seu conteúdo é discutido e estabelecido pelos Estados ou organizações internacionais e, conforme preleciona o professor Paulo Henrique Gonçalves Portela, só será juridicamente vinculante, pelo menos em princípio, com o consentimento desses entes. (2011).

Assim, em que pesem seus eventuais inadimplementos, os tratados internacionais, até os dias atuais, continuam a ser os principais mecanismos de entendimento e cooperação internacionais, em virtude da segurança jurídica que promovem (PORTELA, 2011), de forma que compreender suas origens e analisar sua estrutura configuram-se de suma importância, não apenas em âmbito internacional, mas, também, em relação aos desdobramentos junto aos ordenamentos jurídicos próprios de cada nação.

Para que um tratado internacional possa ser iniciado, os pactuantes devem observar certos requisitos necessários à sua validade, de forma a adequá-lo aos preceitos constantes no texto da Convenção de Viena sobre Direito dos Tratados de 1969 (PORTELA, 2011).

Sob tal prisma, segundo o professor Paulo Henrique Gonçalves Portela, a princípio, o tratado deve obedecer a regras relacionadas à capacidade das partes, à habilitação de seus agentes, a um objeto lícito e possível e a um consentimento regular, por parte das nações ou organizações signatárias (2011).

Tradicionalmente, apenas Estados e organizações internacionais podem celebrar tratados, consoante lição do professor Paulo Henrique Gonçalves Portela.

Destarte, somente Estados soberanos, isto é, aqueles dotados de território, povo e soberania, podem concluir tratados com demais sujeitos de Direito Internacional 
FERREIRA, M. V.; MACHADO JÚNIOR, S. L. P. Tratados internacionais em âmbito interno: uma discussão sobre o ato da denúncia unilateral pelo presidente da república sem a participação do poder legislativo. R. Científica UBM - Barra Mansa (RJ), ano XXII, v. 19, n. 37, 2. Sem. 2017. p. 242-258.

ISSN 1516-4071

(PORTELA, 2011) e, no que tange ao Direito brasileiro, a Constituição Federal de 1988 estabelece:

\author{
Art. 21. Compete à União: \\ I - manter relações com Estados estrangeiros e participar de \\ organizações internacionais;.
}

Outrossim, a Convenção de Viena de 1986 reconheceu a capacidade de as organizações internacionais celebrarem tratados e, não obstante suas normas ainda não estarem em vigor, a atuação dos organismos internacionais, no que tange à conclusão de acordos transnacionais, é pautada, precipuamente, por analogia à Convenção de Viena de 1969, bem como por "normas internacionais costumeiras" (PORTELA, 2011).

Cumpre esclarecer, de início, que, para concluir um tratado, é insuficiente que a parte seja capaz, de forma que, segundo o professor Paulo Henrique Gonçalves Portela, é necessária a existência de um agente que a represente, isto é, dotado do treaty making power, em outras, palavras, do "poder de firmar tratados" (PORTELA, 2011).

Em todo caso, conforme salienta o professor Paulo Henrique Gonçalves Portela, os entes com capacidade para celebrar tratados definirão os indivíduos encarregados de representá-los perante a conclusão de acordos internacionais (2011).

Outrossim, a Convenção de Viena de 1969, em seu artigo 7o, estabelece o rol dos agentes estatais com atribuição para concluir tratados, independentemente de quaisquer autorizações:

\title{
Artigo 7
}

Plenos Poderes

(...)

2. Em virtude de suas funções e independentemente da apresentação de plenos poderes, são considerados representantes do seu Estado:

a) os Chefes de Estado, os Chefes de Governo e os Ministros das Relações Exteriores, para a realização de todos os atos relativos à conclusão de um tratado;

b) os Chefes de missão diplomática, para a adoção do texto de um tratado entre o Estado acreditante e o Estado junto ao qual estão acreditados;

c) os representantes acreditados pelos Estados perante uma conferência ou organização internacional ou um de seus órgãos, para a adoção do texto de um tratado em tal conferência, organização ou órgão. 
Em avanço ao estudo dos requisitos de validade de um tratado, não obstante ser, aparentemente, simples de se compreender, conforme salientam os professores Hildebrando Accioly, Geraldo Eulálio do Nascimento e Silva e Paulo Borba Casella, o objeto de um tratado deve ser lícito e materialmente possível, de forma a não violar o direito, a ética e a moral internacionais. (2012).

Por fim, como último dos requisitos básicos de validade dos tratados, o consentimento dos entes signatários deve ser espontâneo e livre de vícios e distorções que impeçam os pactuantes de expressar suas reais intenções (PORTELA, 2011).

\section{Etapas de elaboração de um tratado}

Em linhas gerais, as etapas de verificação da vontade estatal perfazem, de forma ordenada, a negociação, assinatura, ratificação, entrada em vigor e registro e, de acordo com o professor Paulo Henrique Gonçalves Portela, cabe a cada Estado estabelecer os mecanismos acerca da incorporação do tratado em seu âmbito interno (2011).

Pode-se definir a "negociação" como a etapa preliminar do processo de elaboração de um tratado, isto é, uma ocasião em que os entes signatários estabelecerão as cláusulas, objetivos e diretrizes do ato internacional em apreço (PORTELA, 2011).

Uma vez negociadas as cláusulas e termos do tratado, tem-se a fase de "assinatura" e, como bem conceitua o professor Paulo Henrique Gonçalves Portela:

A assinatura é o ato pelo qual os negociadores, ao chegar a um acordo sobre os termos do tratado, encerram as negociações, expressam sua concordância com o teor do ato internacional, adotam e autenticam seu texto e, por fim, encaminham o acordo para etapas posteriores da formação do ato internacional. (2011, p. 108).

Ademais, o referido doutrinador afirma que, uma vez assinado o instrumento normativo transnacional, enquanto o tratado não começar a vigorar, as partes estão juridicamente vinculadas e, portanto, não podem agir com o fito de comprometer o teor das avenças. (PORTELA, 2011).

Em seguida, há a etapa da "ratificação", que nada mais é do que uma "confirmação", isto é, um ato pelo qual o Estado aceita, definitivamente, as cláusulas do 
tratado, cujo procedimento pode variar, a depender do Estado pactuante (PORTELA, 2011).

Nesse sentido, o respeitável doutrinador menciona que, no Brasil, o ato da "ratificação", de competência privativa do Presidente da República, a princípio, depende de autorização do Congresso Nacional (PORTELA, 2011), de acordo com o artigo 49, inciso I, da Constituição da República:

Art. 49. É da competência exclusiva do Congresso Nacional:

I - resolver, definitivamente, sobre tratados, acordos ou atos internacionais que acarretem encargos ou compromissos gravosos ao patrimônio nacional.

Outrossim, salienta o professor Paulo Henrique Gonçalves Portela que a "ratificação" é discricionária, isto é, poderá ocorrer somente na ocasião mais oportuna aos interesses soberanos do ente estatal, não se vinculando, em regra, a quaisquer prazos e, ademais, é ato privativo do Presidente da República. Embora a "ratificação" seja a "confirmação definitiva de aceitação de um tratado", ainda não se pode vislumbrar a projeção prática de suas pretensões (2011).

Portanto, o douto doutrinador ressalta que, nos tratados bilaterais, há a "notificação da ratificação", isto é, ocasião em que um dos entes informa ao outro que aceitou, definitivamente, o ato internacional e, desta forma, quando ambos os contraentes realizarem as mútuas notificações, o tratado estará pronto a vigorar e produzir seus efeitos (PORTELA, 2011, p. 112).

Por fim, no que tange aos tratados multilaterais, é necessário, como dito anteriormente, para entrar em vigor, um quórum mínimo de ratificações, estabelecido e discriminado no corpo do ato internacional e, atingido o número necessário de confirmações, o tratado produzirá efeitos jurídicos apenas aos Estados que o ratificaram. Após, tem-se a última etapa de formação dos tratados, qual seja o seu "registro". De acordo com o professor Paulo Henrique Gonçalves Portela, a Carta da ONU dispõe que os tratados celebrados por seus membros precisam ser registrados perante seu Secretariado-Geral, a fim de que estejam aptos a serem invocados perante quaisquer de seus órgãos (2011). 


\section{A denúncia unilateral como forma de extinção de um tratado}

A denúncia é mecanismo que extingue um tratado bilateral e, em relação aos pactos multilaterais, cessa seus efeitos no que se refere ao ente renunciante, permanecendo, entretanto, aos demais signatários (PORTELA, 2011).

Como consigna o respeitável professor Paulo Henrique Gonçalves Portela, é de competência interna de cada Estado o estabelecimento dos órgãos competentes para promover a denúncia, bem como suas etapas procedimentais (2011), sendo certo que, porventura, inexistindo normas expressas para regular a temática, posicionamentos divergentes podem se tornar cada vez mais constantes.

Assim, a depender do ordenamento jurídico interno de cada Estado, os procedimentos de tramitação da denúncia podem assumir caráteres distintos, mas que, invariavelmente, culminarão em idêntico propósito: a retirada de um Estado em relação a um compromisso internacional anteriormente firmado. (PORTELA, 2011).

No que tange ao Brasil, o procedimento da denúncia de um tratado, nos termos da legislação nacional, ainda não possui previsão expressa junto à Constituição Federal de 1988, quanto à obrigatoriedade ou dispensa de autorização parlamentar.

Neste sentido, a lacuna procedimental existente enseja a ascensão de posicionamentos doutrinários divergentes, cada qual buscando adequar o procedimento ao que entendem ser o mais razoável, segundo os parâmetros legislativos pátrios.

Como salienta o professor Paulo Henrique Gonçalves Portela, por ora, a denúncia é um ato privativo e discricionário do Presidente da República, não se exigindo autorização prévia ou posterior do Poder Legislativo (2011).

Porém, consigna o referido doutrinador:

Entretanto, existe uma tendência a que passe a ser exigida a autorização congressual prévia para que o Presidente da República possa proceder à denúncia de um tratado. É o que revela o julgamento da ADI 1625, ora em curso, dentro do qual vem prevalecendo a orientação de que não é possível ao Presidente da República denunciar tratados sem o consentimento do Congresso Nacional. (PORTELA, 2011, p. 127). 
FERREIRA, M. V.; MACHADO JÚNIOR, S. L. P. Tratados internacionais em âmbito interno: uma discussão sobre o ato da denúncia unilateral pelo presidente da república sem a participação do poder legislativo. R. Científica UBM - Barra Mansa (RJ), ano XXII, v. 19, n. 37, 2. Sem. 2017. p. 242-258.

ISSN 1516-4071

A referida ADI 1625, ajuizada pela Confederação Nacional dos Trabalhadores na Agricultura (CONTAG) e pela Central Única dos Trabalhadores (CUT) tem como objeto a Convenção 158 da OIT, relacionada ao término da relação de trabalho por iniciativa do empregador, consubstanciada no Decreto $n^{\circ}$ 2.100/1996 e cuja denúncia foi realizada pelo Presidente da República sem a autorização do Congresso Nacional

Destarte, dada a ausência de normas procedimentais atinentes ao instituto, até o julgamento da referida ação direta de inconstitucionalidade, vem prevalecendo, em decorrência de regras consuetudinárias, a falta de necessidade do crivo parlamentar quando da ocasião de eventual denúncia. (COSTA, 2012).

Porém, o doutrinador Valério de Oliveira Mazzuoli defende a tese de que, sendo necessária a autorização parlamentar para ratificar um tratado, igual procedimento, por analogia, deve ser aplicado à denúncia de um ato internacional, visando à efetiva consagração da democracia:

\begin{abstract}
Assim é que, para nós, da mesma forma que o Presidente da República necessita da aprovação do Congresso Nacional, dando a ele "carta branca" para ratificar o tratado, mais consentâneo com as normas da Constituição de 1988 em vigor seria que o mesmo procedimento fosse aplicado em relação à denúncia, donde não se poderia falar, por tal motivo, em denúncia de tratado por ato próprio do Chefe do Poder Executivo (2015, p. 355-356).
\end{abstract}

O professor Francisco Rezek, contrapondo-se à visão defendida por Mazzuoli, defende que a denúncia de um tratado, pelo Poder Executivo, independe de autorização do Poder Legislativo, vez que considera a vontade de um dos Poderes suficiente a ensejar o desligamento do ente estatal em relação a quaisquer compromissos internacionais (REZEK, 2011).

Logo, preleciona o referido doutrinador:

O Estado é originalmente livre de compromissos tópicos: tal o princípio da tabula rasa, segundo o qual toda soberania nascente encontrará diante de si um espaço vazio de obrigações convencionais, preenchendo-o à medida que livremente se ponha, desse momento em diante, a celebrar tratados. Parece bastante lógico que, onde a comunhão de vontades entre governo e parlamento seja necessária para obrigar o Estado, lançando-o numa relação contratual internacional, seja suficiente a vontade de um daqueles dois poderes para desobrigálo por meio da denúncia.(...) (REZEK, 2011, p. 142). 
FERREIRA, M. V.; MACHADO JÚNIOR, S. L. P. Tratados internacionais em âmbito interno: uma discussão sobre o ato da denúncia unilateral pelo presidente da república sem a participação do poder legislativo. R. Científica UBM - Barra Mansa (RJ), ano XXII, v. 19, n. 37, 2. Sem. 2017. p. 242-258.

ISSN 1516-4071

Em suma, para os que defendem tal posicionamento, a comunhão de vontades, entre o Executivo e o Legislativo, é inexigível para que a denúncia ocorra, bastando o ânimo de qualquer deles para pôr termo a um compromisso internacional. (REZEK, 2011).

\section{O instituto da denúncia frente aos tratados internacionais de direitos humanos}

De acordo com o professor André de Carvalho Ramos, em meio à turbulência que permeava a realidade jurídico-brasileira, no tocante ao tratamento que deveria ser conferido aos tratados internacionais de direitos humanos, foi editada a Emenda Constitucional $n^{\circ} 45 / 2004$, que introduziu o $\S^{\circ}$ ao artigo $5^{\circ}$ da Constituição da República (RAMOS, 2014), que assim estatui:

Art. $5^{\circ}, \S 3^{\circ}$. "Os tratados e convenções internacionais sobre direitos humanos que forem aprovados, em cada Casa do Congresso Nacional, em dois turnos, por três quintos dos votos dos respectivos membros, serão equivalentes às emendas constitucionais".

Nesse sentido, a doutrinadora Flávia Piovesan defendeu a existência de duas categorias de tratados de direitos humanos: os materialmente constitucionais; e os material e formalmente constitucionais:

\footnotetext{
Vale dizer, com o advento do $\S 3^{\circ}$ do art. $5^{\circ}$ surgem duas categorias de tratados internacionais de proteção de direitos humanos: a) os materialmente constitucionais; e b) os material e formalmente constitucionais. Frise-se: todos os tratados internacionais de direitos humanos são materialmente constitucionais, por força do $\S 2^{\circ}$ do art. 50. Para além de serem materialmente constitucionais, poderão, a partir do $\S 3^{\text {o }}$ do mesmo dispositivo, acrescer a qualidade de formalmente constitucionais, equiparando-se às emendas à Constituição, no âmbito formal. (PIOVESAN, 2013, p.138).
}

Outrossim, de acordo com o professor André de Carvalho Ramos, a referida emenda constitucional permitiu que o Supremo modificasse sua posição acerca da hierarquia atribuída aos tratados de direitos humanos (RAMOS, 2014). 
FERREIRA, M. V.; MACHADO JÚNIOR, S. L. P. Tratados internacionais em âmbito interno: uma discussão sobre o ato da denúncia unilateral pelo presidente da república sem a participação do poder legislativo. R. Científica UBM - Barra Mansa (RJ), ano XXII, v. 19, n. 37, 2. Sem. 2017. p. 242-258.

ISSN 1516-4071

Floresceu, junto à Suprema Corte, a "teoria do duplo estatuto", que atribuiu caráter constitucional, aos tratados aprovados pelo rito do artigo $5^{\circ}, \S 3^{\circ}$ da Constituição da República e, paralelamente, consagrou status de natureza supralegal aos demais, sejam eles anteriores ou posteriores à emenda constitucional supramencionada, tendo sido aprovados pelo rito comum (RAMOS, 2014).

A doutrinadora Flávia Piovesan, em interessante abordagem acerca dessa temática, e ao estabelecer a divisão entre tratados materialmente constitucionais e aqueles material e formalmente constitucionais, preleciona que os direitos fundamentais, embora considerados cláusulas pétreas, são passíveis de serem denunciados pelo Estado que o celebrou, desde que materialmente constitucionais, apenas, sendo certo que os tratados material e formalmente constitucionais, isto é, aqueles que forem aprovados pelo rito estabelecido no $\S 3^{\circ}$ do artigo $5^{\circ}$ da Constituição da República, são insuscetíveis de denúncia.

Assim, a referida doutrinadora defende a necessidade de comunhão de vontades entre o Poder Executivo e o Poder Legislativo para haver a retirada de um Estado, em relação a um pacto internacional que verse sobre direitos humanos e, como dito anteriormente, seja materialmente constitucional, apenas:

Cabe considerar, todavia, que seria mais coerente aplicar ao ato da denúncia o mesmo procedimento aplicável ao ato de ratificação. Isto é, se para a ratificação é necessário um ato complexo, fruto da conjugação de vontades do Executivo e Legislativo, para o ato de denúncia também este deveria ser o procedimento. Propõe-se aqui a necessidade do requisito de prévia autorização pelo Legislativo de ato de denúncia de determinado tratado internacional pelo Executivo, o que democratizaria o processo, como assinala o Direito comparado (...). (PIOVESAN, 2013, p. 139).

Todavia, em corrente contrária, sustenta o professor Pedro Lenza que os tratados internacionais de direitos humanos material e formalmente constitucionais poderiam, sim, ser denunciados, desde que houvesse prévia autorização do Congresso Nacional, em dois turnos, por três quintos dos votos de seus membros, defendendo, inclusive, a denúncia unilateral, pelo Presidente da República, de um tratado de direitos humanos materialmente constitucional, apenas: 
Enquanto aqueles (tratados de direitos humanos) que seguiram um procedimento mais solene dependem de prévia autorização do Congresso Nacional, também em dois turnos, por 3/5 dos votos dos respectivos membros, em cada uma de suas Casas, os outros (nos mesmos termos daqueles que não tratam sobre direitos humanos) poderão ser denunciados normalmente pelo Executivo, sem a prévia autorização do Congresso Nacional. (LENZA, 2012, p. 609, grifo nosso).

Entretanto, como salienta o professor André de Carvalho Ramos, até o presente momento, não há um posicionamento pacífico do Supremo, em relação à polêmica concernente à denúncia de um tratado de direitos humanos e, nesse sentido, até a adoção de uma orientação em concreto, similar ao que ocorre com os demais tipos de tratados, anteriormente abordados, bastaria a vontade unilateral do Poder Executivo para tanto, ou, mesmo uma lei do Congresso Nacional, que determinasse, ao Presidente da República, a denúncia de um tratado (2014).

\section{A ação direta de inconstitucionalidade n¹625 e seus desdobramentos}

Salienta-se que a polêmica acerca da exigibilidade ou não de autorização legislativa para denunciar um tratado foi suficientemente considerável, a ponto de ensejar uma discussão junto ao Supremo Tribunal Federal, consubstanciada na ADI ${ }^{\circ}$ 1625, ora em curso. (SILVA, 2016).

Cumpre salientar que a Convenção 158 da OIT, mencionada anteriormente, restringia a possibilidade de demissão sem justa causa dos trabalhadores contratados mediante prazo indeterminado e foi ratificada em 4 de janeiro de 1995, cuja internalização ocorreu em 10 de abril de 1996, através do Decreto n 1.855. (SILVA, 2016).

Entretanto, após a correspondente ratificação, começaram a insurgir discussões acerca de sua constitucionalidade, que se materializaram por meio da ADI n 1480 do Supremo Tribunal Federal. (SILVA, 2016).

Com efeito, a denúncia da referida Convenção aconteceu após sete meses, através do Decreto 2.100/1996, o que acabou por ocasionar a perda do objeto da ADI supracitada, que outrora versava sobre a constitucionalidade dos termos daquele tratado. (SILVA, 2016). 
Nisto, uma vez ocorrida a denúncia da Convenção 158 da OIT, a Confederação Nacional dos Trabalhadores da Agricultura (CONTAG) e a Central Única de Trabalhadores (CUT) ingressaram com a ação direta de inconstitucionalidade $\mathrm{n}^{\circ} 1625$, questionando sobre o cerne da presente pesquisa, isto é, a denúncia unilateral, feita pelo Presidente da República, sem a participação do Congresso Nacional. (SILVA, 2016).

Entretanto, as posições dos Ministros do Supremo vinham sendo díspares e, por conseguinte, inexistia unanimidade para o fito de decidir acerca da procedência ou não da referida ADI. (SILVA, 2016).

Destarte, a referida ADI 1625 encontra-se pendente de julgamento definitivo e, com o pronunciamento oficial do STF acerca da temática da denúncia unilateral, pelo Presidente da República, sem a participação do Poder Legislativo, finalmente, decidirse-á entre as posições diversamente sustentadas pela doutrina e, dessa forma, pôr-se-á termo à celeuma jurídica que se instaurou em torno do mencionado instituto. (SILVA, 2016).

\section{Considerações Finais}

Os tratados internacionais exercem, sobre o ordenamento jurídico pátrio, uma influência maior do que a maioria das pessoas pode supor, regulando diversas temáticas de interesse comum entre Estados e organizações internacionais, desde aspectos comerciais e financeiros até ambientais e humanitários.

Em que pese seu inegável protagonismo, tal assunto, infelizmente, não costuma ser abordado pelos acadêmicos do curso de Direito da forma como deveria, eis que se trata de matéria de suma importância, não só por permitir que os países se relacionem civilizadamente, mas, também, por gerar estrondosas repercussões na própria ordem jurídica brasileira.

Tal como evidenciado no decorrer desta monografia, os tratados, como quaisquer outros pactos volitivos, pressupõem o preenchimento de certos requisitos de validade, além de possuírem peculiar estrutura de elaboração, consubstanciada em sucessivas etapas de verificação dos ânimos estatais e organizacionais. 
Portanto, os compromissos internacionais, igualmente, podem extinguir-se, sendo a "denúncia" uma das principais formas de desligamento de um tratado outrora firmado.

Entretanto, a fim de que se possa compreender o instituto da denúncia e suas nuances, é necessário que se conceba como o ordenamento jurídico positivo rege seus mecanismos, em outras palavras, se a denúncia pode ser feita unilateralmente pelo Presidente da República ou se necessita do aval do Congresso Nacional, para produzir seus regulares efeitos.

Conforme exposto, ao findar da presente pesquisa, em que pese os costumes internacionais e a ausência de normas específicas preceituarem que o Presidente da República pode, unilateralmente, rescindir um tratado, via denúncia, há em curso uma ação direta de inconstitucionalidade (ADI n ${ }^{\circ} 1625 / \mathrm{DF}$ ), cujos desdobramentos podem determinar que as denúncias posteriores ao seu desfecho passem a exigir a aprovação do Poder Legislativo.

Com efeito, conclui-se que os tratados devem exigir apreciação congressual para serem denunciados, havendo supedâneo para tanto, de acordo com o posicionamento do doutrinador Valério de Oliveira Mazzuoli que, em sua obra "Curso de Direito Internacional Público, 9a Edição", dispõe que, se para ratificar um tratado é necessária autorização parlamentar, idêntico procedimento deveria ser aplicado para o instituto da denúncia, dada a ausência procedimental na Carta Magna.

Finalmente, espera-se que a referida ação direta de inconstitucionalidade, pendente de parecer definitivo pela Suprema Corte, disponha, definitivamente, acerca do correto procedimento a ser adotado para denunciar os tratados, de forma que a atual lacuna seja cabalmente suprida, a fim de que o referido instituto extintivo se adeque aos preceitos dominantes no atual Estado Democrático de Direito.

\section{Referências}

ACCIOLY, Hildebrando; SILVA, Geraldo Eulálio do Nascimento e; CASELLA, Paulo Borba. Manual de Direito Internacional Público. 20. ed. São Paulo: Editora Saraiva, 2012 .

ARGENTINA. Constitución de la Nación Argentina. Disponível em: 
FERREIRA, M. V.; MACHADO JÚNIOR, S. L. P. Tratados internacionais em âmbito interno: uma discussão sobre o ato da denúncia unilateral pelo presidente da república sem a participação do poder legislativo. R. Científica UBM - Barra Mansa (RJ), ano XXII, v. 19, n. 37, 2. Sem. 2017. p. 242-258.

ISSN 1516-4071

<http://servicios.infoleg.gob.ar/infolegInternet/anexos/0-4999/804/norma.htm>. Acesso em abri1/2017.

BARROSO, Darlan. Direito Internacional - Coleção Elementos do Direito, Volume 11. 3. ed. São Paulo: Editora Revista dos Tribunais, 2011.

BRASIL. Decreto 7.030 de 14 de dezembro de 2009. Disponível em <http://www.planalto.gov.br/ccivil_03/_ato2007-2010/2009/decreto/d7030.htm>. Acesso em abril/2017.

. Decreto 19.841 de 22 de outubro de 1945. Disponível em <http://www.planalto.gov.br/ccivil_03/decreto/1930-1949/d19841.htm>. Acesso em $\mathrm{abril} / 2017$.

Informativo $n^{\circ} 549 \mathrm{STF}$ de $1^{\circ}$ a 5 de junbo de 2009. Disponível em <http://www.stf.jus.br/arquivo/informativo/documento/informativo549.htm>. Acesso em abril/2017.

. Decreto 2.100 de 20 de dezembro de 1996. Disponível em <http://www.planalto.gov.br/ccivil_03/decreto/1996/d2100.htm>. Acesso em abril/2017.

. ADI 1625 - Ação Direta de Inconstitucionalidade. Disponível em $<$ http://www.stf.jus.br/portal/processo/verProcessoAndamento.asp?numero=1625\&class e=ADI\&origem $=A P \& r e c u r s o=0 \&$ tipoJulgamento=M $>$. Acesso em abril/2017.

COIMBRA, Valdinei Cordeiro. Os tratados internacionais e a necessidade ou não de comunhão de vontades para denunciá-los. Portal Conteúdo Jurídico, 2014. Disponível em $<$ http://conteudojuridico.com.br/?colunas\&colunista=2_Valdinei_Coimbra\&ver=1721 >. Acesso em 26 de abril de 2017.

COSTA, Joice Martins da. A denúncia unilateral dos tratados internacionais e a necessidade da participação do Congresso Nacional. Portal Jus.com.br, 2012. Disponível em $<$ https://jus.com.br/artigos/22414/a-denuncia-unilateral-dos-tratados-internacionais-ea-necessidade-da-participacao-do-congresso-nacional>. Acesso em 26 de abril de 2017. 
FERREIRA, M. V.; MACHADO JÚNIOR, S. L. P. Tratados internacionais em âmbito interno: uma discussão sobre o ato da denúncia unilateral pelo presidente da república sem a participação do poder legislativo. R. Científica UBM - Barra Mansa (RJ), ano XXII, v. 19, n. 37, 2. Sem. 2017. p. 242-258.

ISSN 1516-4071

ESPANHA. Constitución Española. Disponível em:

<https://www.boe.es/legislacion/documentos/ConstitucionCASTELLANO.pdf> Acesso em abril/2017.

LENZA, Pedro. Direito Constitucional Esquematizado, 16. ed. São Paulo: Editora Saraiva, 2012.

MAZZUOLI, Valério de Oliveira. Curso de Direito Internacional Público, 9. ed. São Paulo: Editora Revista dos Tribunais, 2015.

PIOVESAN, Flávia. Direitos Humanos e o Direito Constitucional Internacional, 14. ed. São Paulo: Editora Saraiva, 2013.

PORTELA, Paulo Henrique Gonçalves. A possibilidade da denúncia de tratados de direitos humanos no Brasil e o Congresso Nacional. Escola da Magistratura do Rio Grande do Norte: Revista Direito e Liberdade, 2008.

. Direito Internacional Público e Privado, 3. ed. Salvador: Editora

JusPODIVM, 2011.

RAMOS, André de Carvalho. Curso de Direitos Humanos. São Paulo: Editora Saraiva, 2014.

REZEK, Francisco. Direito Internacional Público. 13. ed. São Paulo: Editora Saraiva, 2011.

SILVA, Maria Eduarda Andrade e. Entre Pontes de Miranda e Clóvis Beviláqua: o julgamento da ADI 1625/DF e a discussão em torno do papel do Legislativo no processo de denúncia de tratados internacionais. Portal Conteúdo Jurídico, 2016. Disponível em <http:/www.conteudojuridico.com.br/artigo,entre-pontes-de-mirandae-clovis-bevilaqua-o-julgamento-da-adi-1625df-e-a-discussao-em-torno-do-papel-dolegis,56594.html>. Acesso em 26 de abril de 2017.

URUGUAI. Constitución de la República Oriental del Uruguay. Disponível em <http://www.juntamaldonado.gub.uy/index.php/component/content/article/80.html>. Acesso em abril/2017. 
FERREIRA, M. V.; MACHADO JÚNIOR, S. L. P. Tratados internacionais em âmbito interno: uma discussão sobre o ato da denúncia unilateral pelo presidente da república sem a participação do poder legislativo. R. Científica UBM - Barra Mansa (RJ), ano XXII, v. 19, n. 37, 2. Sem. 2017. p. 242-258.

ISSN 1516-4071

. Ministerio de Relaciones Exteriores: República Oriental del Uruguay -

Tratados: normas de derecho constitucional que rigen en materia de tratados.

Disponível em <http://www.mrree.gub.uy/frontend/page?1,inicio,ampliaciontratados,O,es,0,PAG;CONC;90;9;D;normas-de-derecho-constitucional-que-rigen-enmateria-de-tratados;1;PAG>. Acesso em abril/2017.

VADE MECUM. Constituição da República de 1988. São Paulo: Editora Saraiva, 2017. 